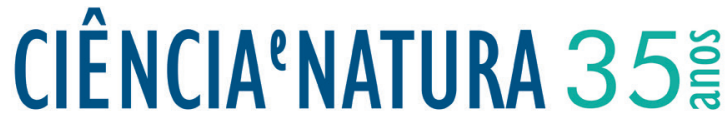

\section{Malthus e a evolução de modelos}

\author{
Malthus and the evolution of models
}

Rodney Carlos Bassanezi*1

${ }^{1}$ IMECC, UNICAMP; CMCC, UFABC

\begin{abstract}
Resumo
Existe, via de regra, uma correspondência entre a evolução de um modelo matemático e a própria evolução da matemática. Esta afirmação é mais evidente quando tratamos de modelos matemáticos de alguma realidade. $O$ estudo da dinâmica populacional dá uma idéia do processo evolutivo dos modelos matemáticos. Os postulados de Malthus que indicavam inicialmente um crescimento populacional exponencial deram origem à formulação de modelos com crescimento inibido. Atualmente, novas técnicas e conceitos matemáticos propiciam novos modelos - é o caso da Teoria fuzzy, dos autômatos celulares e dos sistemas dinâmicos acoplados.
\end{abstract}

Palavras-chave: Modelagem matemática, dinâmica populacional, evolução de modelos.

\begin{abstract}
There is usually a correlation between the development of a mathematical model and the evolution of mathematics. This statement is more evident when dealing with mathematical models of some reality. The study of population dynamics gives an idea of the evolutionary process of mathematical models. The Malthus postulated that initially showed an exponential population growth led to the formulation of models with inhibited growth. Currently, new techniques and mathematical concepts provide new models - it is the case of fuzzy theory, cellular automata and coupled dynamical systems.
\end{abstract}

Keywords: Mathematical modeling, population dynamics, evolution of models.

*rodney@ime.unicamp.br

Recebido: 19/03/2014 Aceito: 19/03/2014 


\section{Introdução}

$\mathrm{A}$ ciência contemporânea é fruto de experiências planificadas e auxiliadas por teorias sujeitas à evolução. A consistência de uma teoria ou sua própria validação tem sido dependente, muitas vezes, da linguagem matemática que a envolve - "Toda teoria específica é, na verdade, um modelo matemático de um pedaço da realidade" (BUNGE, 1974).

Quando se propõe analisar um fato ou uma situação real cientificamente, isto é, com o propósito de substituir a visão ingênua desta realidade por uma atitude crítica e mais abrangente, deve-se procurar uma linguagem adequada que facilite e racionalize o pensamento. $\mathrm{O}$ objetivo fundamental do uso de matemática é de fato extrair a parte essencial da situação-problema e formalizá-la em um contexto abstrato onde o pensamento possa ser absorvido com uma extraordinária economia de linguagem. Desta forma, a matemática pode ser vista como um instrumento intelectual capaz de sintetizar ideias concebidas em situações empíricas que estão quase sempre camufladas num emaranhado de variáveis de menor importância.

O método científico passou a ser constituído da mistura de audácia especulativa com a exigente comparação empírica, e as teorias obtidas passaram a compor sistemas de afirmações com os quais se pode inferir outras afirmações, quase sempre com ajuda da matemática ou da lógica.

Nas pesquisas científicas, a matemática passou a funcionar como agente unificador de um mundo racionalizado, sendo o instrumento indispensável para a formulação das teorias fenomenológicas fundamentais, devido, principalmente, ao seu poder de síntese e de generalização.

O reconhecimento de uma teoria científica passou a ter como condição necessária o fato de poder ser expressa em uma linguagem matemática. A própria matemática teve uma evolução substancial, neste século, em decorrência também da falta de estruturas disponíveis ou adequadas para descrever os fenômenos observados. Por outro lado, o advento dos computadores digitais favoreceu o desenvolvimento e a aplicação da matemática em quase todos os campos do conhecimento.

Quando se procura refletir sobre uma porção da realidade, na tentativa de explicar, de entender, ou de agir sobre ela, o processo usual é selecionar no sistema, argumentos ou parâmetros considerados essenciais e formalizá-los através de um sistema artificial: o modelo. A definição de modelo matemático pode ser encontrada nas mais distintas formas, dependendo do contexto em que esteja inserido. Chamaremos simplesmente de Modelo Matemático um conjunto de símbolos e relações matemáticas que representam de alguma forma o objeto estudado e de Modelagem Matemática o processo dinâmico utilizado para a obtenção e validação de modelos matemáticos. A importância do modelo matemático consiste em se ter uma linguagem concisa que encoraja manipulação e expressa nossas ideias de maneira clara e sem ambiguidades, além de se ter às mãos um arsenal enorme de resultados (teoremas) que propiciam o uso de métodos computacionais para calcular suas soluções numéricas.

Nosso objetivo aqui é mostrar, com um exemplo, a correspondência existente entre a evolução de um modelo matemático e a própria evolução da matemática.

\section{Evolução dos modelos populacionais}

O estudo da dinâmica populacional dá uma ideia do processo evolutivo dos modelos matemáticos. A proposta de utilização de "modelos" para estabelecer o crescimento populacional começou com o economista inglês Malthus (1798). Seu modelo é baseado em dois postulados:

1. O alimento é necessário à subsistência do homem;

2. A paixão entre os sexos é necessária e deverá se comportar, aproximadamente, como um estado permanente.

Supondo que tais postulados estejam garantidos, Malthus (1798) afirma que "a capacidade de reprodução do homem é superior à capacidade da terra de produzir meios para sua subsistência. Assim, a população quando não obstaculizada, aumenta a uma razão geométrica enquanto que os meios de subsistência aumentam apenas em uma razão aritmética. Pela lei de nossa natureza, que torna o alimento necessário à vida do homem, os efeitos destas duas diferentes capacidades devem ser mantidos iguais". Segundo Malthus (1798), a miséria seria, na verdade, um fator positivo, que atuou ao longo de toda a história humana, para equilibrar a desproporção natural entre a multiplicação do homem e a produção de alimentos.

Apesar da proposta de Malthus para o crescimento populacional ter dois postulados, o que se tornou conhecido como Modelo de Malthus foi apenas o crescimento exponencial. Tal modelo assume que a população cresce como uma progressão geométrica, isto é,

$$
P_{n+1}=r P_{n} .
$$

Assim, dada uma população inicial $P_{0}$, em $\mathrm{n}$ anos esta população seria $P_{n}=r^{n} P_{0}$.

Neste caso, se considerarmos o crescimento populacional teremos:

$$
P_{n+1}-P_{n}=(r-1) P_{n} .
$$

ou seja, o crescimento de uma população é proporcional à população em cada instante, e desta forma a população humana deveria crescer sem nenhuma inibição se $r>1$. 
Salientamos que apesar deste modelo ser baseado numa expressão matemática muito simples mesmo para época em que foi formulado, não foi Malthus que o fez - ele apenas usou variáveis linguísticas em seus postulados.

O Modelo de Malthus propõe um crescimento de vida otimizada, sem fome, guerra, epidemia ou qualquer catástrofe, onde todos os indivíduos são idênticos, com o mesmo comportamento. A previsão da população mundial, segundo o modelo malthusiano, atingia números astronômicos em pouco tempo o que tornaria a Terra um planeta superlotado e inabitável. Também as previsões drásticas em relação à alimentação estavam equivocadas pois não se supunha o grande salto que ocorreu na produção mundial de alimentos entre os anos de 1950 a 1998, quando passou de 247 quilos per capita para 312 quilos (REVISTA VEJA, 1999). De qualquer forma, a humanidade que levou milhares de anos para atingir o primeiro bilhão de pessoas, em menos de dois séculos conta com 6 bilhões.

No modelo de crescimento populacional sem inibição a taxa de crescimento intrínseco (natalidade menos mortalidade) r é considerada constante e positiva. Modelos mais realísticos pressupõem que esta taxa seja uma função da população e decrescente com o tempo.

A modelagem matemática para descrever o crescimento populacional evoluiu, passando por várias modificações após Malthus. Um dos modelos mais importante e conhecido é do sociólogo belga P. F. Verhulst (1838 apud MURRAY, 1990) que supõe que toda população é predisposta a sofrer inibições naturais em seu crescimento, devendo tender a um valor limite constante (capacidade suporte) quando o tempo cresce. É um modelo de crescimento mais significativo, do ponto de vista biológico pois usa, de fato, os dois postulados de Malthus.

Os modelos de Malthus e Verhurst foram formulados para tempo contínuo, onde se supõe que os indivíduos se reproduzem a todo instante, o que na realidade poucas populações biológicas satisfazem. Os modelos discretos podem ser considerados mais realísticos, neste caso, uma vez que contemplam a reprodução dos indivíduos sazonalmente - tais modelos, em Ecologia, foram introduzidos somente a partir de 1975 pelo ecólogo austríaco Robert M. May que observou a complexa dinâmica do modelo logístico discreto sob a luz da teoria do caos, mostrando que uma equação de aparente ingenuidade pode ter solução sem comportamento previsível (MURRAY, 1990).

As formulações estocásticas dos modelos determinísticos de Malthus e Verhurst só apareceram a partir de 1924 (Yule), sendo usados posteriormente por Bailey, em 1964, e Pielou, em 1977 (MURRAY, 1990).

Na década de 40, Leslie (1945-48), modelou o crescimento populacional compartimentalizando a população por idade e estudando o fluxo entre os compartimentos através da álgebra matricial.

Os modelos matemáticos de interação entre espécies foram independentemente formulados, através de equações diferenciais por Lotka e Volterra (1926 apud MURRAY, 1990). Seus famosos modelos de competição e predação têm servido de parâmetros para uma infinidade de outros modelos, embora possam ser considerados extremamente simplistas para atenderem à complexidade inerente à natureza dos seres vivos. Por outro lado, as tentativas de se medir o fator competição na natureza, utilizando os métodos clássicos, não produziram resultados satisfatórios. A própria subjetividade, advinda de termos como competição e complexidade, sugere o uso de novas ferramentas matemáticas. Alguns trabalhos recentes, usando a Teoria Fuzzy, são dedicados às medidas dessas variáveis subjetivas (BARROS; TONELLI; BASSANEZI, 2000).

De qualquer forma, um modelo matemático pode dar apenas uma aproximação de algum fenômeno da realidade. Um fato curioso ocorreu quando manchetes de todos os meios de comunicações anunciaram o nascimento do bebê de número 6 bilhões - a previsão para tal evento dava como certo o dia 12 de outubro de 1999 às 11 horas e dois minutos (horário de Brasília). Evidentemente este fato estava baseado em algum modelo matemático determinístico incontestável mesmo porque não existiria maneira possível de testá-lo. No entanto, é claro que a probabilidade de se ter acertado é quase nula, basta ver que a previsão para este acontecimento fora anteriormente dada como sendo 16 de junho. Esta diferença, aparentemente insignificante, acarreta uma diminuição na população de, aproximadamente, meio bilhão de pessoas em 50 anos. Entretanto, o que se pode afirmar com alguma convicção é que a Terra tinha na ocasião, aproximadamente, 6 bilhões de pessoas, o que não deixa de ser preocupante.

\section{A subjetividade matemática}

A previsão do crescimento populacional de um país ou de uma região é fundamental para avaliar sua capacidade de desenvolvimento e estabelecer mecanismos que sustentem uma produção compatível com o bem estar social. Entretanto, modelos matemáticos não se prestam apenas para previsões, eles podem também ser utilizados para desvendar o passado. Neste caso, uma simples coleta de dados pode fornecer elementos para uma análise estatística do fenômeno passado, por exemplo, dados cartoriais podem fornecer informações regionais sobre variáveis relacionadas com casamento, nascimento, morte, etc. e com isto, é possível recuperar a história da região. Salientamos que valores obtidos com a análise de dados estatísticos são valores aproximados ou incertos. A incerteza, proveniente da aleatoriedade de eventos, ocupa um lugar de destaque no elenco da matemática, com ênfase na área de estudos probabilísticos. A Teoria da Probabilidade tem como foco central a explicação da possível ocorrência de cada evento, baseada numa distribuição de ocorrências passadas. 
Muitas vezes quando modelamos certas situações da realidade, as variáveis linguísticas são imprecisas ou subjetivas e nem sempre dispomos de distribuições estatísticas ou aleatórias para fazer alguma avaliação aproximada, no sentido usual. Nestes casos, devemos empregar outra estratégia de avaliação distinguindo ou qualificando as variáveis por meio de graduações ou de meias-verdades. Assim, se estamos interessados em classificar elementos de uma população pela cor da pele, usando apenas três categorias Branco, Pardo e Negro, a matemática clássica faz uma distinção absoluta de cada elemento - um indivíduo pardo não é nem branco ou negro. Entretanto, na realidade tal distinção é bastante subjetiva, basta ver os gêmeos que foram classificados como pardo e branco para o ingresso na UnB. Uma maneira de tratar as variáveis linguísticas subjetivas, como as do caso anterior, é por meio da lógica fuzzy onde, as fronteiras dos conjuntos podem ser imprecisas - um mesmo elemento pode pertencer a dois ou mais conjuntos, tendo a cada um deles um determinado grau de pertinência. Se dissermos que um indivíduo é branco com grau de pertinência 0,8 e pardo com grau de pertinência 0,4 , simplesmente queremos dizer que ele é mais branco que pardo.

Se quisermos entender um fenômeno de migração entre regiões, muitas variáveis subjetivas entram no processo: Fertilidade, Fecundidade, Mortalidade, Morbidade, Ambiente, etc. Um especialista pode dar informações como: "Se o ambiente é hostil, então a fecundidade é baixa, a mortalidade é alta e a emigração é alta". Neste caso, devemos estabelecer padrões ou funções de pertinência para cada uma das variáveis linguísticas e, utilizando uma base de regras, formada por inferências como a anterior, podemos criar um modelo que dá a dinâmica de populações de regiões que têm fluxos migratórios. É claro que quanto mais subjetividade existir no processo menos certeza temos na solução - também, quanto mais complexo for o sistema menos chance temos que nosso modelo matemático represente o fenômeno precisamente. Zadeh (1965) expressa bem este fenômeno com seu Princípio da Incompatibilidade: “Conforme a complexidade de um sistema aumenta, nossa habilidade de fazer afirmações precisas e significativas sobre seu comportamento diminui, até um limiar em que a precisão e relevância tornam-se praticamente características mutuamente exclusivas". Em relação à modelagem matemática Einstein (1921) é mais contundente: "Quando as leis da matemática se referem à realidade, elas não são certas. E se são certas, não são referentes à realidade". - De qualquer forma, estas afirmações por mais verdadeiras que sejam, não devem desanimar o modelador que sempre busca se aproximar cada vez mais da verdade com seus modelos matemáticos.

\section{Referências}

BARROS, L. C.; TONELLI, P.; BASSANEZI, R. C. Fuzzy modelling in population dynamics. Ecological Modelling, 128, 27-33, 2000.

BARROS, L. C.; BASSANEZI, R. C. Tópicos de Lógica Fuzzy e Biomatemática. Coleção IMECC - Textos Didáticos, 5. Campinas: IMECC-UNICAMP, 2006.

BASSANEZI, R. C.; FERREIRA JR., W. Equações Diferenciais com Aplicações. São Paulo: Harbra, 1988.

BASSANEZI, R. C. Ensino-aprendizagem com modelagem matemática. São Paulo: Contexto, 2002.

BUNGE, M. Teoria e Realidade. São Paulo: Perspectiva, 1974.

EDELSTEIN-KESHET, L. Mathematical Models in Biology., New York: Random-House Ed., 1988.

EINSTEIN, A. Geometry and experience. In: Ideas and opinions. Berlin: Springer-Verlag, 1921.

LOTKA, A. J. Elements of Physical Biology. Baltimore: Williams \& Wilkins, 1925.

MALTHUS, T. R. An Essay on the Principle of Population; Ed. Johnson, in St Paul's Church-Yard, 1798.

MAY, R. M. Simple mathematical models with very complicated dynamics. Nature, 261, 1976.

MURRAY, J. D. Mathematical Biology. 2a ed. Berlin: Springer-Verlag, 1990.

REVISTA VEJA, 39, set. 1999. pp.86-89.

SCUDO, F. M.; ZIEGLER, J. R. The Golden Age of Theoretical Ecology: 1923-1940. Lectures Notes in Biomathematics, 22. Berlin: Springer-Verlag, 1978.

VOLTERRA, V. Le ${ }_{s}$ cons sur la th'eorie mathematique de la lute pour la vie. Paris: Gauthier-Villars, 1931.

ZADEH, L. A. Fuzzy Sets. Information and Control, 8, 338-353, 1965. 